\title{
perifèria
}

Número 9, diciembre 2008

www.periferia. name

\section{Procesos educativos y redes solidarias en comunidades devastadas por el huracán Stan}

\author{
Neptali Ramírez Reyes. Máster en Investigación Etnográfica, Teoría \\ Antropológica y Relaciones Interculturales. UAB ${ }^{1}$.
}

\begin{abstract}
Resumen
Este documento describe las experiencias vividas durante una brigada de apoyo solidario a las Comunidades Chiapanecas devastadas por el huracán Stan durante el mes de diciembre 2005. La brigada "Tortuga" fue construida de manera espontánea por un grupo de estudiantes de licenciatura, quienes con el apoyo de diversos profesores de la Universidad Iberoamericana-Puebla recibieron entrenamiento y soporte para responder al llamado de diversas organizaciones de la región afectada. El documento alterna un formato testimonial y académico y reproduce el espíritu de la experiencia misma: la colaboración entre los actores (estudiantes y funcionarios universitarios) que buscan tejer una forma de situarse en la realidad. El objetivo que persigue este trabajo es la sistematización de la manera en que se articuló la construcción de un tejido de relaciones y esfuerzos solidarios motivados por la necesidad de generar conocimiento pertinente para la formación de actores universitarios capaces de incidir en realidades emergentes. Las labores de gestión universitaria continuamente orientadas a la búsqueda de diseños educativos que privilegien escenarios reales de formación obligan a los funcionarios universitarios a mantener una activa construcción de tejidos y relaciones solidarias con actores diversos.
\end{abstract}

Palabras clave: Redes de apoyo, procesos educativos, organización local, actores sociales.

\begin{abstract}
This document is the description of the experiences Developer by a solidarity support brigada working with Chiapas communities devastated by the Stan hurricane in December 2005. The "Tortugas" brigada was integrated by a group of collage students trained by Universidad Iberoamericana-Puebla sholars in response to the call of local organization in the damaged region. The presentation incluides testimonial and academia aspects and reproduces the spirit of the experience collaboration between academics and students in creating the strategic support approach. It offers the way that it was created linking motivation and abilities to knowledge building needed to confront unexpected troubles. The experience has been the search for educational approaches that look for actual training settings building solidarity networks with actors involved in facing social challenges.
\end{abstract}

Key words: Solidarity support, educational processes, college training, local organization, social actors.

\footnotetext{
${ }^{1}$ Correo electrónico: neprare@gmail.com
} 


\section{perifèria}

Número 9, diciembre 2008

www.periferia. name

\section{Una experiencia humana}

Las redes de apoyo que se tejieron entre los habitantes de las comunidades pertenecientes al municipio de Chicomuselo, Chiapas, a raíz de los efectos del huracán Stan con la Universidad Iberoamericana-Puebla, fue una experiencia humana y de cercanía con el sufrimiento. Ahí estuvimos caminando por veredas y durmiendo donde hubiera un espacio. Ahora con el paso del tiempo, sabemos que esta vivencia dejó huella en cada uno de los que conformamos la "Brigada Tortuga" 2 .

La Brigada fue una respuesta entusiasta de todos los involucrados y crucial ante la urgencia de atender a la población afectada por el fenómeno natural. La red que se tejió, antes como ahora sigue siendo ineludible. El contacto humano activo y comprometido es humanamente necesario, más aún cuando se está inmerso dentro de la formación psicológica, donde un compromiso extra, un criterio de autentico servicio al otro se ha de hacer patente.

\section{Chiapas una vez más}

En la primera semana de octubre de 2005, el huracán Stan llegó a Chiapas, estado ubicado en el sureste de la Republica Mexicana. Fue de tal magnitud el impacto de este fenómeno natural, que las lluvias no cesaron en varios días, hubo deslaves en carreteras, puentes derrumbados, los ríos se desbordaron y miles de personas perdieron todo: casa, cosechas y animales.

Los medios de comunicación difundieron imágenes que dejaban entrever que la situación era grave en las ciudades con mayor población. Sin embargo, pese a toda la información que fluía, se desconocían los efectos de la magnitud del fenómeno en las zonas rurales y marginadas, ya que éstas habían quedado incomunicadas.

\footnotetext{
${ }^{2}$ Grupo integrado por diez alumnos y una profesora de psicología de la Universidad Iberoamericana Puebla. Erika Cruz, Javier Valencia, Maria Eugenia Cid, Fernanda Gallego, Cinthya Olvera, Begoña Gallego, Valentín Méndez, Miriam Meza, Guadalupe Chávez y Cecilia Ortiz integraron la Brigada Tortuga.
} 


\section{perifèria}

Número 9, diciembre 2008

www.periferia.name

La ausencia de información veraz en torno a las comunidades alejadas, sólo evidenciaba que el problema era complicado, pero no se imaginó que fuera particularmente duro. Las lluvias disminuyeron y entonces hubo información en relación a la situación de algunas comunidades en la sierra:

(...) los estragos de Stan en esta zona de la sierra de Chiapas comienzan a ser visibles desde la cabecera del municipio de Frontera Comalapa, pues a lo largo de 60 kilómetros, hasta Motozintla, decenas o cientos de viviendas quedaron destruidas total o parcialmente (C. Ciro. Comunicación Personal. 05 de diciembre, 2005).

En Chiapas una vez más se había centrado la atención y no era casualidad.

\section{Mientras tanto, en la universidad}

En la Universidad I beroamericana-Puebla, cada vez que la situación así lo requiere, se activa el centro de acopio de víveres. Para ello, algunos estudiantes cooperan con parte de su tiempo para estar pendiente y recoger todo cuanto se aporte, ahí “llegaron varias compañeras a apoyar, los mismos de siempre, los que acuden a las juntas de broncas estudiantiles, los que asisten a los eventos de la universidad, la gente participativa" (J. Valencia. Comunicación Personal. 08 de enero, 2006). Ante las noticias de los efectos del huracán Stan, no se podía hacer una excepción, la respuesta era necesaria. Los días iban transcurriendo y las necesidades de la población afectada se hacían más grandes. Mientras tanto, en la universidad las clases seguían su curso normal. Días después, a unos estudiantes nos llegó información para formar parte de una brigada para que fueran a Chiapas. La situación era difícil y se requería de la atención emocional de las personas que fueron afectadas por el huracán Stan.

La invitación era tentadora, tanto para quienes no se conforman con las prácticas de campo y las clases, como para quienes buscan constantemente el contacto humano:

(...) debía haber algo que pudiera hacer que no fuera donar latas (que no podía comprar) o ropa (que no tenía). Podía ir, insistía en que yo quería ir a entregar las despensas, un contacto más directo ( $\mathrm{J}$. Valencia. Comunicación Personal. 10 de enero, 2006). 


\section{perifèria}

Número 9, diciembre 2008

www.periferia. name

Para otros más, representaba la oportunidad de no culminar la licenciatura en las aulas, sino dentro de un contexto que requería no sólo destreza profesional, sino fortaleza y templanza humana, sensibilidad para estar con quien lo necesita y llevar a cabo un intercambio recíproco dentro de una red en pie de igualdad (Adler, 1998: 63). Fue así como motivos diversos llevaron a cada uno a formar parte de la brigada, pero se coincidía en que se quería apoyar en todo cuanto fuera necesario.

\section{EI efecto mediático pasó}

Es común que ante los efectos de un fenómeno natural la ayuda fluya en los primeros días. Después se olvida a la población afectada. Es entonces cuando los problemas se agudizan, porque se dan soluciones mediáticas a situaciones complejas. No existe por tanto, una respuesta integral e institucional que proporcione acompañamiento a las personas ante un escenario adverso. La situación en Chiapas así fue, con mucha difusión en los medios de comunicación, pero poco o nulo trabajo con las personas:

(...) los pobres de la Sierra de Chiapas, le han dado al país lecciones de dignidad: no se organizaron ni para robar, ni para asaltar; se organizaron para ayudarse unos a otros (D. Gumaro. Comunicación Personal. 11 de diciembre, 2005).

El efecto mediático del huracán Stan pasó, pero atrás de éste había humanos que no fueron tomados en cuenta.

La situación era que los problemas reales comenzaron a recrudecerse. Algunos estudiantes lo intuyeron, así que ante la invitación, una respuesta positiva sería lo congruente. Sin embargo, no se trataba solamente de responder afirmativamente, sino de estar dispuesto antes de partir a Chiapas, a someterse a un curso intensivo de primeros auxilios y de intervención en crisis. Además, se tendría que dejar todo en orden con los profesores de las asignaturas que cada uno se encontraba cursando:

(...) espero que la turbulencia de fin de semestre les sea llevadera y reconozco el grandísimo esfuerzo que están haciendo en esta doble jornada estudiantil y también universitaria (C. Cuétara. Comunicación Personal, 03 de diciembre, 2005). 


\section{perifèria}

Número 9, diciembre 2008

www. periferia.name

Porque el hecho de asumir ésta responsabilidad no excluía dejar todo inconcluso. No era una invitación a la aventura, sino que se trataba de una forma concreta de situarse ante la realidad, ante los efectos de un fenómeno natural que había dejado secuelas, no sólo materiales.

\section{El ímpetu y el deseo por ayudar no bastan}

La respuesta que en un principio se visualizaba como algo fácil, no lo fue tanto. El curso intensivo de primeros auxilios en situación de emergencia nos mostró, que ante un escenario adverso el ímpetu y el deseo por ayudar no bastan, incluso pueden complicar una situación aparentemente controlada. No fuimos pocos quienes nos cuestionamos si en verdad estábamos haciendo bien al decidir participar en la brigada. El estrés simplemente acumulado en el curso de primeros auxilios, era suficiente para retractarse, continuar con las clases normales y finalizar el curso como siempre; sin problemas y todo tranquilo. Pero no, se mostró disposición a trabajar con mayor intensidad para terminar con todo cuanto se considerara necesario para un mejor desempeño de la intervención social.

En el curso de intervención en crisis fueron similares los cuestionamientos y semejantes nuestras actitudes; se evidenció disposición a situarse responsablemente ante la realidad, puesto que es necesario prepararse solidamente si en verdad se desea servir a quién así lo requiere. La buena voluntad es insuficiente cuando ésta no procede acompañada de una consistente preparación. Es con humanos con quienes tratamos, "así me di cuenta que la psicología social, no era simplemente teoría sino que casi todo se basaba en la acción" (F. Gallegos. Comunicación Personal. 12 de enero, 2006).

\section{En bien de la brigada}

Si bien los cursos fueron intensos y la preparación una experiencia necesaria, el trabajo en equipo no se podía excluir. Se conformaron parejas de trabajo. Cada uno era responsable de si mismo y del otro. Para esto, la actitud personal de tolerancia y respeto a las diferencias facilitarían las acciones que se realizarían en beneficio de la población afectada. Más aún, se requería del apoyo mutuo constante, sincero y 


\section{perifèria}

Número 9, diciembre 2008

www.periferia.name

cercano.

Si bien los que estamos inmersos dentro del mundo de la psicología conocemos las dificultades propias del trabajo en equipo, esto no implica de ninguna forma, que sea más fácil hacerlo realidad. Así que se compartió ampliamente, se asumió la responsabilidad de traducir en hechos concretos nuestras actitudes y trabajar durante todo el tiempo que fuera necesario en bien de la brigada "era fundamental saber que, si era fortaleza y recursos humanos los que íbamos a ofrecer, los primero que teníamos que estar bien éramos nosotros" (G. Chávez. Comunicación Personal. 17 de enero, 2006), para llevar a cabo una mejor intervención con la población a la que se habría de atender.

Ante la respuesta para conformar la brigada, la universidad se adaptó a las necesidades formativas que requerían sus estudiantes:

(...) quiero manifestarles nuestra profunda convicción de que el grupo que ustedes han consolidado tiene grandes posibilidades de ofrecer horizontes de esperanza en la comunidad que nos ha llamado (F. Fernández. Comunicación Personal. 20 de noviembre, 2005).

La universidad de ésta forma realizó una evaluación para garantizar que quienes participarían llegaran en completa capacidad física y emocional para poder aportar soluciones.

\section{Por fin Ilegamos a Chiapas}

Después de realizar todo cuanto se consideró necesario, dejar resuelta cada situación con los profesores, cumplir con la preparación previa, documentarse teóricamente, ponerse las vacunas y reunir las casas de campaña, nos dispusimos a partir. Sabíamos que nuestra respuesta no era mediática, sino como se ha esbozado en párrafos anteriores, era una forma de situarse ante la realidad

Salimos de Puebla y por fin llegamos a Chiapas, a San Cristóbal de las Casas exactamente, donde todo estaba normalizado. Las integrantes del Colectivo de Feministas Mercedes Olivera y Bustamante, A. C. (COFEMO) nos informaron con mayores detalles la situación general de las comunidades de Chicomuselo y cómo se había estado llevando a cabo la intervención psicosocial. Se ratificó al siguiente 


\section{perifèria}

Número 9, diciembre 2008

www.periferia.name

día, que se partiría a la zona de Chicomuselo, lugar situado en la Sierra Madre de Chiapas y que colinda con Siltepec, Bella Vista, Frontera Comalapa, la Concordia, Socoltenango y Ángel Albino Corzo.

Estando ya en Chicomuselo y hospedados en la bodega parroquial, los compañeros de la Comisión del Movimiento de Resistencia Popular del Sureste (CMRPS), nos indicaron los lugares a los que habríamos de realizar la intervención psicológica. Las comunidades fueron: San Antonio Ocotal, Ojo de Agua, Palo Largo, Zacualpa, Mal Paso, El Triunfo, Vado Ancho, Nuevo San francisco, Pacayal, Nueva Esperanza, Lázaro Cárdenas, Tejería y Barrio la Junta, todo ubicado en el municipio de Chicomuselo. Pocas veces, sino es que nunca, estos lugares ocuparon un espacio en los medios de comunicación.

El Colectivo de Feministas Mercedes Olvera, A. C. (COFEMO) nos informaban que la situación real de las comunidades no era nada grata:

(...) los hombres ante la inactividad están consumiendo alcohol y esto puede agravar la situación de violencia hacía las mujeres. Hay dificultades para que se organicen. Las pocas acciones asistencialistas que ha realizado el gobierno, más que ayudar, están generando división y conflictos que no favorecen en nada la rehabilitación de las comunidades (Y. Castro. 10 de noviembre, 2006).

\section{Nuestras impresiones}

La estructura organizacional tenía un avance bastante significativo en Chicomuselo y fueron ellos quienes decidieron, en función de sus necesidades, las comunidades o ejidos que se habrían de visitar. En efecto, se confirmó que "ante todo queremos respetar la estructura organizativa del municipio, no crear otras y que ustedes tengan la relación directa con estos comités" (G. Cárdenas. 11 de noviembre, 2006). Llegamos a sumarnos, a adaptarnos y, en función de nuestras capacidades, a responder a una población que así lo requería, ya que "nosotros como universidad pretendemos justamente eso, integrarnos a iniciativas que la propia comunidad ya tenga en marcha" (F. Fernández. Comunicación Personal. 15 de noviembre, 2006). 


\section{perifèria}

Número 9, diciembre 2008

www. periferia. name

Lo que se observó con regularidad en las mujeres era la constante impotencia, tristeza, nostalgia por lo perdido, el sentimiento de que el desastre había sido castigo divino y miedo porque volviera a suceder otra vez lo mismo. El desamparo, el agotamiento físico-emocional, la tensión muscular y la ansiedad eran evidentes, las personas lo exteriorizaban en las intervenciones "el corazón me duele, se me hace un nudo en la garganta, me mareo, se me nubla la vista y me duele la cabeza" (P. Hernández. Comunicación Personal. 17 de diciembre, 2005). No pocas personas ya habían asistido con el médico de la Secretaría de Salubridad y Asistencia (SSA) de Chicomuselo, pero éste nunca encontraba nada médicamente diagnosticable.

Los niños en algunas comunidades evidenciaban una agresividad constante, en otras estos tenían pesadillas y ya no se sentían seguros después de lo acontecido. La tristeza por la pérdida del patrimonio y por estar viviendo en un lugar que no era su hogar, fue lo que más verbalizaron. Los hombres mayores de edad, se mostraban enojados por lo sucedido y por la ausencia de cooperación intracomunitaria. Mencionaban que el gobierno los tenía abandonados, estaban tristes y no era evidente ninguna respuesta a sus problemas. El resentimiento contenido y la desesperación se percibían constantemente. Ellos compartían sentir "dolor de cabeza" y en ciertas partes del cuerpo ante la tragedia ocurrida.

\section{Lo que vimos, sentimos y escuchamos}

\section{La red de apoyo}

No sabemos como era el paisaje antes del huracán Stan, pero lo que observamos fueron calles ahora convertidas en ríos, puentes destruidos, cosechas perdidas, árboles derribados, agua sucia, personas que había perdido sus casas, animales y objetos materiales "la gente está preocupada porque no habrá cosecha, el problema en un futuro no lejano será preocupante" (N. Ramírez. Diario de Campo. 18 de diciembre, 2005). En efecto, para contrarrestar tal situación, era importante acompañar al individuo en la comunidad a encontrar los mecanismos eficaces y juntos, volvieran a buscar con sus propios medios las formas de salir de la situación adversa en la que se hallaban. 


\section{perifèria}

Número 9, diciembre 2008

www.periferia. name

Si bien las pérdidas materiales fueron importantes, las consecuencias psicológicas eran particularmente complicadas. Al respecto Bateson (Milanese, Merlo y Machin 2000: 43-45) refiere que los nudos y los vínculos (emocionales y sociales) contribuyen a la estabilidad (individual y grupal) y por lo tanto a la permanencia y seguridad de una red, ésta existe cada vez que se da una relación que se caracteriza por ser persistente, reciproca y prevalente. Sin embargo, en Chicomuselo, Chiapas, la destrucción del espacio físico tornó vulnerable el equilibrio psicológico individual y fragilizó la estructura social.

En medio de este escenario también observamos la solidaridad entre los mismos miembros de la comunidad y su decisión por solicitar el apoyo profesional a la Universidad Iberoamericana-Puebla. Al respecto French (Requena, 2003: 65) refiere que el liderazgo consiste en la capacidad de un miembro para influir en los demás, tanto directa como indirectamente, en virtud de su posición en la estructura de poder, incluida la estructura de autoridad legitima. Por ello, el liderazgo puede estar distribuido entre muchos miembros o concentrado sólo en pocos; la pauta de liderazgo es más una distribución que describe a todo el grupo, que a un atributo de individuos concretos.

En efecto, la red de apoyo se generó a partir de las necesidades en las comunidades. De hecho, ya en medio del trabajo con la población poco a poco los participantes se daban cuenta y compartían "estábamos afligidos porque no sabíamos que hacer, hasta que encontramos la solución" (J. Márquez. Comunicación Personal. 13 de diciembre, 2005). De este modo, se volvía a pensar en la comunidad para superar el escenario adverso, como es propio en las comunidades indígenas.

Asimismo, nos dimos cuenta que las intervenciones que realizábamos con las personas les servía para revitalizar la necesidad de apoyarse, encauzar las diferencias en la comunidad y recuperarse juntos del siniestro. Es así como: 


\section{perifèria}

Número 9, diciembre 2008

www.periferia. name

(...) los compañeros se mostraban reflexivos, optimistas y satisfechos, ya que después de cada actividad, había participación constante y definían con claridad tanto lo que sentían como lo que podían hacer. Identificaban recursos humanos como la unidad, la confianza, la comunicación y el apoyo (P. Valdés. Comunicación Personal. 21 de diciembre, 2005).

\section{Disposición y ánimo}

El trabajo fue intenso. Para llegar a algunas comunidades se tuvo que caminar, porque únicamente de esta forma se podía acceder:

(...) dejamos las cosas y caminamos hacía la zona afectada por la crecida del río, este panorama fue el más desolador que habíamos visto, el río se extendió a lo ancho alrededor de un kilómetro y arrancó árboles, destruyendo con ellos las casas. Seguimos caminando hasta un punto donde lo que veíamos nos dobló las rodillas y nos obligó a sentarnos; todo el equipo se quedó ahí unos minutos (E. Cruz. Diario de campo. 14 de diciembre, 2005).

En las comunidades dormimos donde hubiera un espacio y siempre hubo disposición y animo para dirigir las actividades. La convicción de que se estaba haciendo lo pertinente, era una motivación cuando una vez terminado el trabajo en cada poblado, se sentía un ambiente diferente, "estaban muy conmovidos pues sin saber con certeza desde donde veníamos constantemente daban las gracias por nuestra presencia" (N. Ramírez. Diario de campo. 17 de diciembre, 2005). Al respecto Saidón (Dabas y Najmanovich, 1995:333) argumenta que la red en muchos casos es la posibilidad de gestar un plano de consistencia donde la organización fija y estereotipada ceda su dominio a procesos de creatividad e invención.

De hecho, el nombre de la brigada, no surgió del equipo, sino de las personas con las que se trabajó en Vado Ancho. Quienes nos vieron descansar referían que "cuando se despertaron y abrieron sus bolsas de dormir parecían como tortuguitas saliendo de su caparazón". Es así como a partir de ese momento fuimos llamados "La Brigada Tortuga". 


\section{perifèria}

Número 9, diciembre 2008

www. periferia. name

\section{Situarse en la realidad}

\section{Conscientes de la situación política}

Si bien nos preparamos física, emocional y profesionalmente antes de salir, no sabíamos si nuestro bagaje en estos tres ejes sería tanto pertinente como útil y si respondería a las necesidades que nos íbamos a encontrar. De cualquier forma, la brigada tenía la disposición de adecuarse en todo momento al escenario que se habría de encontrar. El diagnóstico de antemano había sido estrés, depresión, división y conflictos que no favorecían la rehabilitación de las comunidades. Se requería por tanto:

(...) estar conscientes de la situación política que atraviesan las regiones y las brigadas podrían trabajar en grupos de mujeres y hombres por separado, porque la atención individual sería algo más tardado y difícil de realizar (G. Cárdenas. Comunicación Personal. 22 de noviembre, 2005).

En efecto, así fue. Conocíamos la fragilidad política del contexto en el que nos encontrábamos y fuimos cuidadosos al respecto. Se respetó el plan de acción que el Movimiento de Resistencia Popular del Sureste diseñó, así como las fechas exactas y la hora concreta a la que arribaríamos a cada comunidad. Al respecto Dabas (1995: 43) refiere que la construcción de la realidad toma en cuenta las costumbres, los valores, los mitos y tabúes de los grupos, y es a partir de entonces cuando un grupo se propone una realidad alternativa, facilitando de esta manera el desarrollo de un consenso que pueda proveer la base para nuevas reorganizaciones.

Se visitaron trece comunidades y en cada una de ellas con regularidad se trabajaba formando un grupo de mujeres, otro grupo de hombres (ambos adultos) y uno más tanto de niñas como de niños. La cantidad de personas variaban de una comunidad a otra, así que una vez que la Brigada arribaba a cada localidad y sabiendo con exactitud el número de participantes, se podían hacer más grupos de cada uno de los tres sectores atendidos. Solamente en una ocasión se trabajó con un grupo de jóvenes, quienes rescataron el hecho de "aprender a trabajar en colectivo y recuperar la confianza". 


\section{perifèria}

Número 9, diciembre 2008

www. periferia.name

\section{La cercanía con las personas}

Se sabe que ante los efectos de la magnitud de un desastre, las secuelas psicológicas son importantes. Sabíamos de antemano que nuestra brigada no llevaba recetas de soluciones para las comunidades. Así que nuestro trabajo se centró más bien, en facilitar que fueran ellos quienes discernieran, quienes se dieran cuenta de los recursos individuales y colectivos con los que contaban para continuar con más solidez todo cuanto ya habían estado haciendo antes de nuestra llegada.

La cercanía con todas las personas fue fundamental, por ello siempre al inicio de las actividades en cada comunidad se reunía a todos los presentes, nos presentábamos y se explicaba el por qué y para qué estábamos ahí. Asimismo, preguntábamos cómo preferían trabajar. Esto es importante ya que existen configuraciones comunitarias que se tienen que respetar y porque nuestra intervención era de corto plazo.

En efecto, con los niños y niñas siempre nos esmeramos por conocer sus nombres, después se llevaban a cabo actividades lúdicas, se dialogaba en torno a lo sucedido en el desastre y cómo se sentían ante éste hecho. Esto permitía que los niños compartieran lo que estaban vivenciando:

(...) si bien a ellos les costaba más trabajo verbalizar lo que estaban experimentando, ya que la reacción ante el suceso se había transformado en actitudes hostiles hacía sus compañeros" (V. Méndez. Comunicación Personal. 22 de diciembre, 2005).

El trabajo no fue tan sencillo. Se finalizaba compartiendo lo que habían aprendido en la reunión y cómo podían ponerlo en práctica.

\section{Externar lo que estaban experimentando}

Con las mujeres el trabajo fue similar, en las diversas comunidades visitadas se mostraron sensibles y compartieron sin dificultad sus miedo y vivencias, además de compartir las pérdidas que habían sufrido, se mostraron participativas y motivadas para trabajar. 


\section{perifèria}

Número 9, diciembre 2008

www.periferia. name

En otras ocasiones, al principio mostraban incertidumbre y desconfianza, pero conforme avanzaban las dinámicas aprovechaban la oportunidad para externar lo que estaban experimentado a raíz del desastre: enojo, impotencia, dolor y tristeza la mayoría de las compañeras Iloró. Esto último aparentemente simple no lo es, ya que en las comunidades marginadas, a raíz de los efectos del fenómeno natural, si bien existía cooperación mutua, ésta no era del todo eficiente porque aún prevalecían una serie emociones individuales contenidas, que obstaculizaban o estaban difiriendo una reacción más comunitaria para enfrentar la adversidad. Se compartieron diferencias y disensos, con ello se facilitó el consenso que posibilitó la creación de un contexto que permitió la continuación del trabajo comunitario con mayor eficiencia o evolutivo como le nombra Dabas (1995).

Con los hombres hubo ligeras variaciones en las intervenciones. En ocasiones había dificultad para profundizar, se mostraban resistentes, estaban tristes, porque no veían respuesta gubernamental ni para sus cosechas. El estado de indefensión en el que se encontraban era evidente, pero no se daban cuenta de su situación. Ante este contexto la dinámica del "nudo" (los participantes se "amontonan", levantan los brazos, toman la mano "más distante" de otro compañero y juntos sin hablar, han de encontrar la solución y desatar el "nudo" que se ha generado) resultó ser siempre oportuna, útil y eficaz para inducir la analogía con la realidad que estaban vivenciando. Hasta que encontramos la solución

Lo anterior generaba una coyuntura donde los hombres se confrontaban a sí mismos. Con esto se propiciaba un espacio de reflexión, dialogo y solución a las adversidades en las que estaban inmersos. En las sesiones de intervención las personas manifestaban que estaban afligidos porque no sabían qué hacer, hasta que encontraban la solución por medio de las dinámicas aplicadas en las intervenciones.

Es así como el patrón seguido en el desarrollo de las intervenciones se pueden resumir de las siguientes formas: a) inducción por medio de una actividad lúdica comunitaria para que el individuo realizara analogías con la situación que estaban vivenciando; b) discerniera que estaba pasando consigo mismo; c) externara sus sentimientos y se escuchara para con ello darse cuenta de qué acontecía en su 


\section{perifèria}

Número 9, diciembre 2008

www.periferia. name

entorno inmediato; d) cómo podía encauzar su situación personal y e) lograr una mayor eficiencia comunitaria ante los efectos propiciados por el huracán Stan. Como nos habremos dado cuenta, la intervención en las comunidades atendidas se adecuó a su cosmovisión; pues en las comunidades indígenas primero se piensa en la comunidad y luego en el individuo.

Indudablemente, así actuaron ante el paso del huracán, pero tiempo después, cada uno buscó una solución particular, lo que complicó el bienestar comunitario, por esto el problema se hacía más evidente. Lo que necesitaban eran intervenciones que facilitaran la posibilidad de restablecer la armonía comunitaria y comenzar a tejer desde ahí una red de apoyo.

\section{El impacto de la intervención}

Llegamos a Chicomuselo Chiapas y realizamos las intervenciones en las diferentes comunidades cuando el problema realmente estaba agudizándose, cuando el efecto mediático ya había pasado, cuando realmente se sentían los efectos por la destrucción de las casas, por las pérdidas de los animales y la absoluta ruina de las cosechas. En éste contexto nos situamos y nos limitamos a acompañar, a escuchar, a inducir una actitud que era necesaria: el accionar comunitario. Al respecto Quinceno (2005:4) refiere que es importante tener en cuenta que paralelo a la destrucción del espacio físico se hallan efectos traumáticos sobre la población. Las pérdidas humanas, como un primer factor, la destrucción del territorio y el impacto que recibe la estructura social, puede traducirse en la fragmentación de las distintas formas organizativas y las relaciones internas del grupo. De igual manera, los colectivos afectados se enfrentan a nuevas situaciones que implican cambios en su manera tradicional de organizarse, lo que puede traducirse en el aumento de conflictos políticos y sociales, evidenciando la complejidad de todos los factores que sostienen la organización social.

Una vez que se concluía cada sesión, las personas que participaron nos compartían “¿de dónde salio la respuesta?, pues de acá". Sus rostros se transformaban, había un sentimiento de unidad, de cooperación y deseo por volver a reunirse para propiciar mayores vínculos en la comunidad. Quedó comprendida la necesidad de 


\section{perifèria}

Número 9, diciembre 2008

\section{www. periferia. name}

apoyarse para solucionar los conflictos de la comunidad generados por los efectos del huracán Stan.

Las y los compañeros identificaron sus recursos humanos, se mostraron reflexivos, agradecidos, contentos, satisfechos y en sus semblantes se podía percibir ánimo:

(...) hubo llanto al despedirnos, pocas veces la comunidad tiene visitas externas, son muy cariñosos y expresivos, se percibió por los abrazos que nos dieron y las trenzas que hicieron en el cabello de algunas compañeras (M. E. Cid. Comunicación Personal. 23 de diciembre, 2005).

La intervención tuvo impacto doble; primero con las personas a las que se atendió y después, en nuestro proceso formativo en la universidad. Fue un contacto humano. La compañía se hizo mutua y el deseo por volver se construyó a partir de esa realidad. Más adelante, otros compañeros realizaron el Servicio Social Integral ${ }^{3}$ en las mismas comunidades donde tiempo atrás habían estado interviniendo. Al respecto Dabas (1995:44) argumenta que la realidad se construye en la interacción de redes sociales y es así como la intervención en red y sus efectos, constituyen una modalidad participativa que favorece la resolución de problemáticas comunes que aquejan a una comunidad, a una institución o un grupo de sujetos.

\section{El último día}

Después de recorrer las trece comunidades y estar en contacto con las personas, volvimos nuevamente a la cabecera municipal. Ahí nos reunimos para comentar nuestras impresiones con los compañeros que conformaban la Comisión del Movimiento de Resistencia Popular del Sureste, a quienes se entregó un reporte de cada una de las comunidades que fueron atendidas.

\footnotetext{
3 Es una praxis formativa que permite a los alumnos de la Universidad Iberoamericana - Puebla colaborar con los sectores más vulnerables de la sociedad mediante una propuesta de solución a problemas socioprofesionales expresadas por estos y el fortalecimiento de las competencias propias de los sujetos sociales. Se realiza fuera de Puebla en comunidades urbanas, rurales, campesinas e indígenas. El estudiante tiene que radicar en la región un mínimo de 5 meses. El trabajo académico y de acompañamiento es proporcionado por un profesor/a de la universidad que radica en la región de trabajo y con quién los estudiantes cursan seminarios de reflexión e investigación.
} 


\section{perifèria}

Número 9, diciembre 2008

www.periferia. name

Paralelamente al trabajo del día, con sigilo otras personas del pueblo preparaban una algo especial; nos invitaron a cenar un día antes de partir. Nuestra sorpresa fue importante, no se esperaba que en medio de las carencias que ellos estaban teniendo, tuvieran una actitud que dejó huella en cada un@ de quiénes conformamos la "Brigada Tortuga".

Realmente no ansiábamos recompensa alguna, puesto que las satisfacciones ya las habíamos recibido a cada instante al estar con la gente. No obstante, el último día, la gente que había convivido con nosotros nos preparó una cena y en el lugar de la fiesta:

(...) nos hablaron de los talleres y de lo agradecidos que estaban porque fuimos, ellos lo sintieron como un acompañamiento en el dolor por el que estaban atravesando y nadie había tenido esa atención. Nos dijeron que las dinámicas y los juegos que hicimos los ayudaban a reconocer que entre todos podían salir mejor de esa difícil situación y nos despidieron con abrazos y sonrisas (N. Ramírez. Diario de campo. 23 de diciembre, 2005).

Con las imágenes descritas en los párrafos anteriores, regresamos a la Universidad con un equipo sólido que tiempo después se transformo en una brigada de intervención oficial.

\section{Conclusiones}

Los desastres son ocasiones para el cambio social, esto ya ha sido documentado por la antropología (Mancha, 2005). Por esto, forjar redes entre las universidades, los alumnos y los diversos sectores sociales es no sólo pertinente, sino útil y necesario, pues el mundo está formado por redes (Molina, 2001). De tal modo que en la ausencia de uno de los tres ejes no hay verdaderos procesos educativos. Estos procesos no son un recurso mediático, sino una forma de actuar ante el tiempo que se vive, ante el espacio que se pisa, ante la necesidad de seguir contribuyendo en la construcción de un tejido de relaciones solidarias, que respondan a la urgencia de la realidad experimentada tanto por la universidad, los alumnos y los sectores sociales que necesitan del acompañamiento. El beneficio es mutuo ya que se teje una forma de situarse en la realidad y una red que no desliga al alumno del compromiso social. 


\section{perifèria}

Número 9, diciembre 2008

www.periferia.name

Es así como el presente documento, surgido dentro de un contexto académico, es parte de un proceso de reflexión, que ha tenido como origen un fenómeno natural y sus consecuencias, la convocatoria a formar redes solidarias desde la universidad y la respuesta comprometida de estudiantes de psicología.

\section{Referencias bibliográficas}

Adler, L. L. (1998). Redes sociales, cultura y poder. Ensayos de antropología latinoamericana. México, D. F.: Porrúa / FLACSO.

Dabas, N. E. (1995). Red de redes. Las prácticas de la intervención en redes sociales. Buenos Aires, Argentina: Paidós.

Dabas, N. E., Najmanovich, D. (1995). Redes. El lenguaje de los vínculos. Hacía la reconstrucción y el fortalecimiento de la sociedad civil. Buenos Aires, Argentina: Paidós.

Mancha, C. O. (2005). El tsunami del 26 de diciembre: la oportunidad para un cambio de escala global. Revista de Antropología I beroamericana. Núm. 39.

Molina, J. L. (2001). El análisis de redes sociales. Una introducción. Barcelona, España: Bellaterra.

Milanese, E., Merlo, R., Machin, J. (2000). Redes que previenen. México, D. F.: Instituto Mexicano de la Juventud.

Quinceno, M. C. N. (2005). Escenarios de una catástrofe. Revista de Antropología I beroamericana. Núm. 39.

Requena, S. F. (2003). Análisis de redes sociales. Orígenes, teorías y aplicaciones. Madrid, España: Siglo XXI. 